\title{
Research of Ship Maintenance Management Platform Based on Cloud Computing
}

\author{
Liu Xin ${ }^{1, a}$,Zhang Qiang ${ }^{1, a}$, Wang Shouba ${ }^{1, a}$, Cheng Xiangxin ${ }^{1, a}$,Tang Junjie ${ }^{2, a}$ \\ ${ }^{1}$ Shandong Jiaotong University Maritime College, Weihai, 264200; \\ ${ }^{2}$ Yankuang GROUP, Zaozhuang 277599 \\ aaxinzaixian@163.com
}

Keywords: ship; the maintenance management system; cloud computing

\begin{abstract}
The digital management of shipping business information is an inevitable trend. Compared with traditional management mode, it's more convenient, efficient and traceable. The maintenance management platform based on Cloud Computing manage the business information, providing platform service for other systems also, which will make it become the core and information hub of ship information management.
\end{abstract}

\section{Introduction}

Trouble-free operation of the ship for shipping company is the biggest cost savings. To realize the trouble-free operation of the ship, the priority is to strengthen the maintenance management. The most complicated and important link in ship management is maintenance management. Ensuring ship in sustained and stable work condition has a significant meaning on reducing the company's operating costs as well as finishing the transportation plan.

In our country, maintenance information management system experience the phases of spreadsheets, information management systems, Web applications,etc. It is in moving towards a higher stage, namely the fourth generation of ship maintenance management platform or ship maintenance management platform which is based on ship maintenance management. It is a cloud computing platform that complete all kinds of ship information management system integration.

This paper studies the maintenance management system which is an information management system for shipping companies.based on cloud computing platform Through comprehensive management of the equipment, spare parts, materials, certificate, voyage, maintenance of, it makes the ocean and coastal and inland river ships safer, management more scientific and efficient.

\section{System introduction and features}

\section{System introduction}

Maintenance management system was born in the 1980s with the convenient and efficient information management in the shipping industry has been rapidly promoted. Nowadays, most of ships on international routes are equipped with the system. It is integrated of marine equipment and spare parts management, ship maintenance plan formulation and inspection, certification management, ship material management, warehouse management, cost management, crew management, ship voyage management and report management, etc business management functions. Maintenance management platform based on cloud computing is a system that:cloud computing technology as the core, the Internet as the carrier, providing services such as infrastructure, platform, software. Computing model is the integration of large-scale scalable computing, storage, data, application of distributed computing resources to work together. Data, applications and services is stored in the cloud rather than the local computer or remote server. Users make full use of the data center with powerful computation ability, realize the adaptability of maintenance management system and its extended system.

Cloud computing is the third change of global IT industry and a new hot spot in the development of IT industry in recent years. The core idea of cloud computing is managing and 
scheduling a large number of network computing resources uniformly, then constituting a virtualized computing resources pool, providing customers with the services required to improve the utilization of information resources.

Cloud computing is a calculation model providing users with configurable, shared basic resources. It makes users convenient, real-time get access to the network, storage and computing resources, under the condition of the cloud service providers rarely participated. Cloud computing providers connect a large number of nodes and network devices together to build one or several large-scale data center. Then on the basis of the data center, it provides customers with various levels of service, such as infrastructure services, platform service, storage services and software services, etc. Cloud computing has the characteristics of large scale, high scalability, high reliability, virtualization, on-demand service and low price, etc. It can well meet the requirements of mass data storage.

\section{System characteristics}

Maintenance management platform based on cloud computing integrates and manages all business information about operation. And it is the core and the hub of the ship information management,as well as provides the framework and platform services for extended service. Maintenance management platform based on cloud computing has the following features:

Comply with ship maintenance system, plan maintenance system, cycle maintenance system, and so on a variety of Marine equipment maintenance management system.

Complete ship-shore data synchronization mechanism at cloud, support cloud data acquisition at any time, place.

Strong cloud storage, cloud computing, cloud services.

Docking business data platform of the competent authority,business platform with real-time data acquisition.

Providing the platform service to extension system.

Compatible with the remote fault diagnosis and rule out, remote medical treatment, intelligent energy consumption monitoring and so on functions.

\section{The system structure}

Cloud computing architecture is divided into four layers, from top to bottom are: SOA build layer, management middleware layer, resource pool layer, and the physical resource layer. SOA build layer conducts a encapsulation of cloud computing ability, which in turn,constitute a standard Web Service Service, and put into the SOA architecture for the management and use. Management middleware layer is mainly used to manage all kinds of resources in cloud platform, the application of large task scheduling, which can make full use of various resources. Resource pool layer is responsible for processing the vast amounts of resources to form the resource pool of isomorphism or close to, such as computing resources pool, storage resources pool, data resource pool, etc. Physical resource layer is responsible for the physical resources needed to provide a cloud platform and its related software and hardware equipment, including computers, storage, database, and all kinds of application software, etc. In the four layers architecture, resource pool layer and management middleware layer is the most critical part, and the function of SOA component layer is mainly rely on external facilities to realize.

The ship maintenance management system based on $\mathrm{B} / \mathrm{S}$ architecture is working in a cloud computing architecture. All kinds of data resources stored in the cloud, broadband satellite communication between a ground station is the process of the cloud data transformation and renewal. Connection between a ground station and the external network such as the Internet or LAN is realized in WAN way. Through the SAN way, ground station is connected to the ship side Internet computing resources to realize the remote backup and file storage. Users get the corresponding various application service through the Internet from the computer.

PaaS take software development platform as a service and submit to users in SaaS model, and SaaS provides software through the Internet without buying software, but providers rent web-based 
software, the data transmission between shore end and on the ship is through the broadband satellite.

Ship base end can process the data according to the priority of the data differently.The high priority data conducts real-time data communications by maritime satellite, low priority data can be stored in ship servers temporarily. When the ship offshore, data synchronization by WAN or GPRS can greatly reduce the cost of satellite communication.

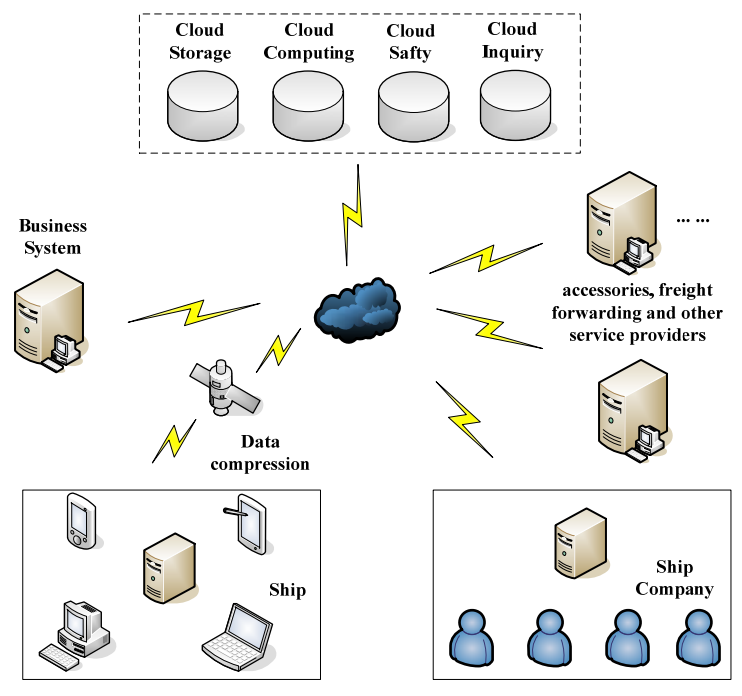

Fig 1 The structure of the system

\section{System function}

\section{Basis functions}

Maintenance management system has eight modules: marine equipment and spare parts management, ship maintenance plan formulation and inspection, certification management, ship material management, warehouse management, cost management, crew management, ship voyage management and report management. On this basis, the maintenance management platform based on cloud computing can provide platform services for other systems as well as realize remote fault diagnosis and maintenance, dynamic monitoring of energy consumption, the bridge on duty monitoring, remote medical treatment, cargo monitoring, and other system extension.

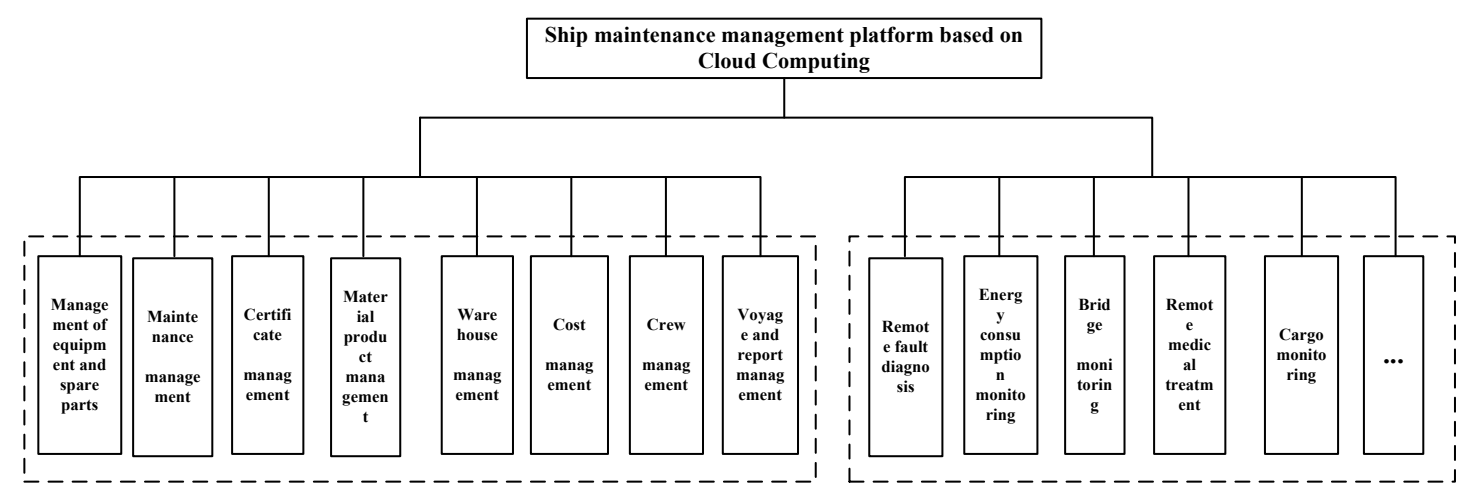

\section{System extension function}

Fig 2 The function of the composition

1) Intelligent energy consumption monitoring system

In ship operation cost, fuel cost occupied a high proportion. With the rising of fuel costs and improvement of energy conservation and emissions reduction standars, more and more owners began to seek feasible way to energy conservation from management, operation, new technologies, etc. Adjusting the fore and aft draft can effectively reduce the ship sailing resistance, which is an energy conservation and emissions reduction technology recommended by IMO. Its basic principle 
is: the ship sailing resistance is influenced by speed, displacement, draft and trim angle.

The ship can sail on the best state by adjusting the float state. Intelligent energy consumption monitoring system uses the Internet of things technology to acquire real-time parameters such as energy consumption, draft, load, and conduct model calculation according to the parameters, then put out the optimal adjustment scheme of trim and form work record uploaded to the cloud platform.the company can view real-time operation of the ship.

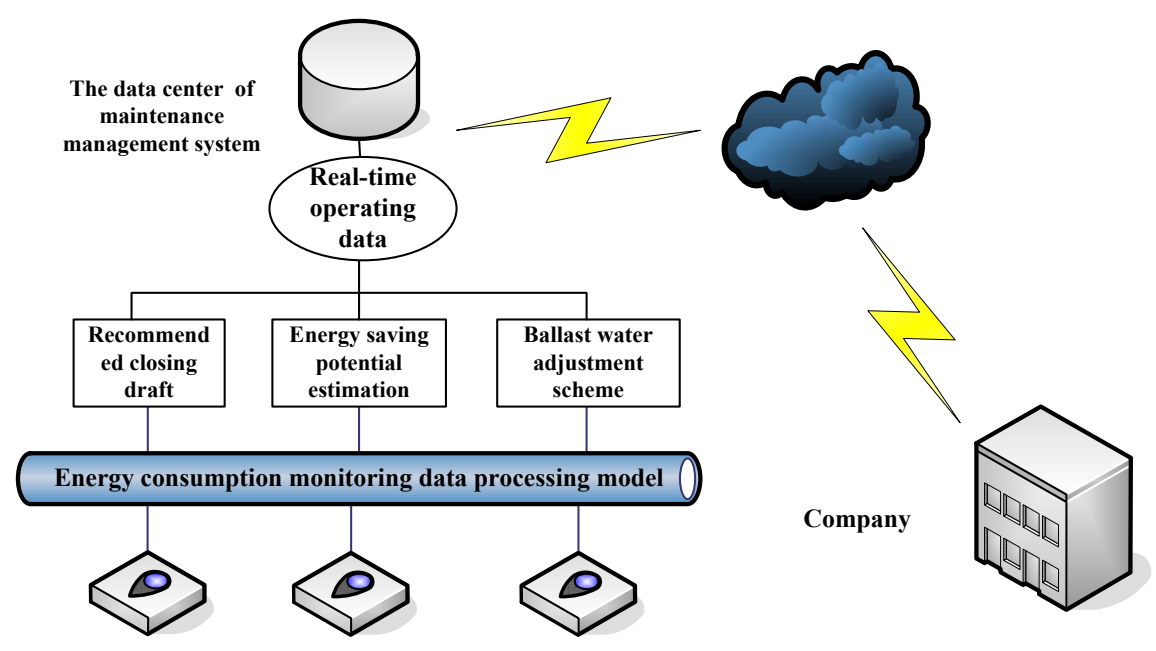

Fig 3 The structure of energy consumption monitoring system

2) Bridge navigational watch alarm

Abbreviations for Bridge Navigational Watch Alarm System is BNWAS. the main function is to prevent the officer fails to perform its duties when sailing on duty and avoid the ship at risk of unmanned situation.

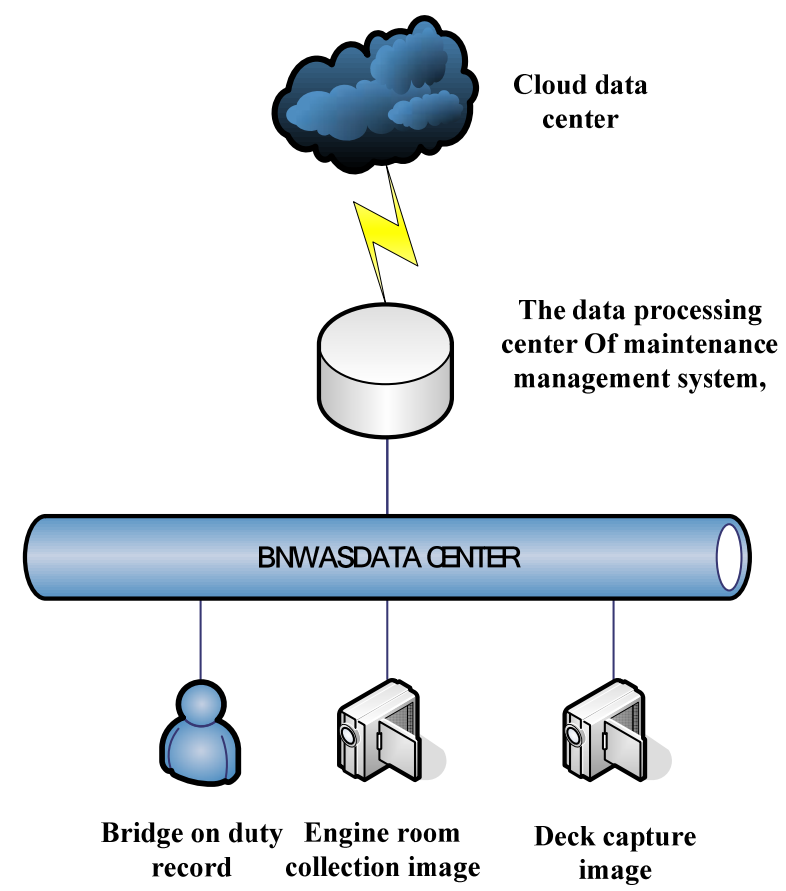

3) Marine diesel engine remote fault diagnosis

At present, marine diesel engine fault diagnosis technology has been developed from maintenance strategy based on time to the predictive maintenance strategy based on state.And the requirement of diesel engine on-line monitoring has been more and more high. Using the remote fault diagnosis technology can timely know the operation condition of marine diesel engine.when the system detects that the marine diesel engine is abnormal or has fault symptoms, taking action 
quickly, do not let the failure happen or maintenance in advance. So it can make the performance of diesel engine best with the least amount of cost, and avoid marine diesel engine occur accident or cause economic losses and casualties to ensure the safe, stable and reliable running of the ship.

\section{Summary}

With the advancement of shipping informatization, marine intelligent system is emerging constantly. But the system is unable to realize the interaction and integration independently, so it bring great inconvenience and waste to the user. The maintenance management system based on cloud computing can provide cloud services for system integration of different system resources. It will surely become an important carrier for shipping informatization and the development direction in the future.

\section{Acknowledgements}

This work was financially supported by the Project of Shandong Jiaotong University Natural Science Foundation(No: Z201403).

\section{References}

[1] Zheng shijun. Design and analysis of ship safety and technology management system [J]. Navigation of China, 2002 ,(4):64-68.

[2] Zhe qiancheng, Design and implementation of ship maintenance management platform [D]. Dalian Maritime University.2011.

[3] Bai hongfen, The design of ship maintenance management system based on B/S [D]. Jimei University.2013. 